\title{
Сорбция триарилметановых красителей полимерами с молекулярными отпечатками
}

\author{
Хальзова С.А., Зяблов А.Н., Дуванова О.В. \\ ФГБОУ ВО «Воронежский государственньий университет», Воронеж
}

Поступила в редакцию 31.01.2017 г.

\begin{abstract}
Получены изотермы сорбции триарилметановых красителей (E131, E133, E142) полимерами с молекулярными отпечатками и их полимеров сравнения. Определены значения максимальной сорбционной емкости сорбентов по отношению к красителям, на основании которой оценены площади проекции молекул красителей на поверхность сорбента. Определены значения степеней извлечения и коэффициентов распределения, рассчитан импринтинг-фактор. Установлено, что полимеры с молекулярными отпечатками на основе полиимида обладают лучшей сорбционной способностью по отношению к целевым молекулам, чем их полимеры сравнения.

Ключевые слова: триарилметановые красители, сорбция, полимеры с молекулярными отпечатками, импринтинг-фактор.
\end{abstract}

\section{Sorption of dyes bases polymers with molecular imprints}

\author{
Khalzova S.A., Zyablov A.N., Duvanova O.V. \\ Voronezh State University, Voronezh
}

\begin{abstract}
This work is devoted to study of the sorption properties of polymers with molecular imprints bases dyes and their polymers comparison. Polymers with molecular imprints triarylmethane dyes on the basis of polyimides (the original monomers - 1,2,4,5-sensortechnology acid and 4,4'-diaminodiphenyloxide) obtained by non-covalent imprinting. The square projections of the molecules on the surface of the modified polymer for all colors exceed the calculated area values of the molecules, which indicates a leaky filling in the surface of the sorbent and the likely orientation of the molecules close to parallel to the surface of the sorbent. In sorption of anionic particles of colorants to the surface of the adsorbent acquires a partial negative charge, which complicates the sorption with increasing surface concentration of sorbate. Orientation of dye molecules in the adsorption layer are probably close to parallel to the surface of the sorbent. For synthetic dyes obtained high values of the imprinting factor, which allows the use of polymers with molecular imprints of the dye as a modifier of piezoelectric sensors for selective determination bases of the dyes in liquid media.
\end{abstract}

Keywords: triarylmethane dyes, sorption, polymers with molecular imprints, imprinting factor.

\section{Введение}

Синтетические пищевые красители в настоящее время широко используются в различных отраслях. Особое место среди них занимают триарилметановые красители, они представляют собой соли слабых оснований. По параметрам острой пероральной токсичности синтетические пищевые красители можно отнести к 3-му и 4му классам опасности. Именно поэтому предельно допустимая концентрация пищевых добавок жестко нормируется санитарными нормами. Рекомендуемые дозировки красителей в безалкогольных и алкогольных напитках следующие: желтые и оран-

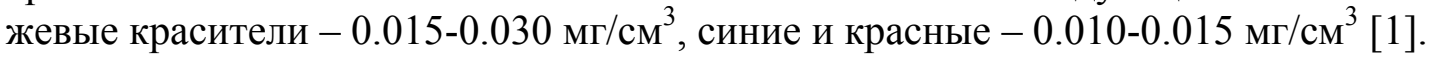


В настоящее время разрабатываются различные способы определения синтетических красителей в продуктах питания. Одними из перспективных являются пьезосенсоры на основе полимеров с молекулярными отпечатками (ПМО) [2]. Для успешного применения ПМО в качестве селективных материалов сенсоров необходимо исследовать их свойства. Поэтому целью работы было изучение сорбции триарилметановых красителей полимерами с молекулярными отпечатками.

\section{Эксперимент}

Ароматические полиимиды получали из продукта АД-9103 ТУ-6-19-283-85 производства ОАО МИПП НПО «Пластик» (Москва). АД-9103 представляет собой смесь исходных мономеров 1,2,4,5-бензолтетракарбоновой кислоты и 4,4'-диаминодифенилоксида.

В качестве молекулы-шаблона использовали триарилметановые красители: синий патентованный V (E131), бриллиантовый синий FCF (E133), зеленый S (E142). Методом нековалентного импринтинга [3] были получены полимеры с молекулярными отпечатками красителя на основе полиимида.

Изучение сорбции проводили в статическом режиме. Навеску ПМО и ПС массой 0.015 г помещали в $5 \mathrm{~cm}^{3}$ водного раствора красителя, при постоянном перемешивании выдерживали 30 мин. Содержание красителя в водной фазе определяли на спектрофотометре ПЭ-5300В («Промэколаб»). Для Е131 при длине волны 638 нм, для Е133 - при 630 нм, для Е142 - при 632 нм [4].

Стандартные растворы красителей готовили из реактивов квалификации

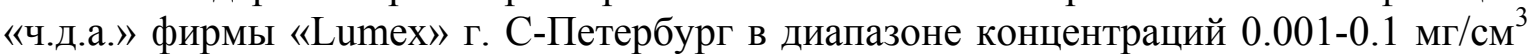
методом последовательного разбавления из $1 \mathrm{mг} / \mathrm{cm}^{3}$. Эксперименты проводили при температуре $20 \pm 1^{\circ} \mathrm{C}$.

По полученным данным рассчитывали величины степеней извлечения $(\mathrm{R}, \%)$ и коэффициентов распределения (D). Способность сорбента с молекулярными отпечатками красителей распознавать молекулу-темплат оценивали с помощью импринтинг-фактора:

$$
I F=\frac{D_{\Pi М О}}{D_{\Pi С}},
$$

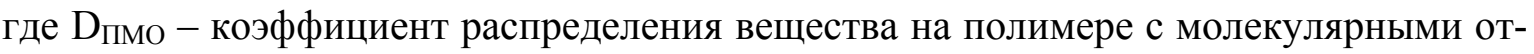
печатками, $\mathrm{D}_{\text {пс }}$ - коэффициент распределения вещества на полимере сравнения [5].

По методике, описанной в работе [6], рассчитывали удельную поверхность полимера с молекулярными отпечатками красителя, определяли максимальную сорбционную емкость сорбента, на основании которой оценены площади проекции молекул красителей на поверхность сорбента $\left(\mathrm{S}_{\mathrm{i}}\right)$ [7] по формуле:

$$
S_{i}=\frac{S_{\text {уд }} \cdot 10^{21}}{A_{m} \cdot N_{A}},
$$

где $\mathrm{S}_{\mathrm{yд}}$ - удельная поверхность сорбента $\mathrm{m}^{2} / \Gamma, \mathrm{A}_{\mathrm{m}}-$ максимальная сорбционная емкость ммоль $/ г, \mathrm{~N}_{\mathrm{A}}$ - число Авогадро, $6.02 \cdot 10^{23}$ моль $^{-1}$.

\section{Обсуждение результатов}

При получении полимеров с молекулярными отпечатками красителей комплексы мономеров полиамидокислоты с шаблонами фиксируются в определенных позициях жесткой полимерной структуры. Последующее удаление шаблона приво- 
дит к появлению в полимере молекулярных отпечатков - полостей, комплементарных шаблону по размеру, форме и расположению функциональных групп. Благодаря «молекулярной памяти», заложенной в полимерной решетке, эти участки способны к повторному специфическому взаимодействию с шаблоном или его структурным аналогом [8].

В ходе проведенных экспериментов были получены кинетические кривые сорбции и изотермы сорбции красителей. Время установления равновесия составляет 30 мин. Изотермы сорбции для полимера с молекулярным отпечатком красителя и его полимера сравнения имеют сходный характер. В водных растворах красители E133, E142 находятся в виде однозарядных анионов, а краситель Е131 - в виде биполярного иона. В первичной структуре полиимида [9] присутствуют активные атомы водорода, функциональные группы: $-\mathrm{OH},-\mathrm{NH},-\mathrm{C}=\mathrm{O}$, поэтому сорбция красителей E133, E142 может осуществляться за счет электростатических взаимодействий анионных форм красителя с поверхностью полимера, а сорбция красителя Е131 за счет образования водородных связей с сорбентом.

Для красителя E131 (рис. 1) сорбция описывается изотермой L-типа, вероятно взаимодействие адсорбат-адсорбент больше, чем адсорбат-растворитель. На начальном этапе наблюдается резкое увеличение сорбции красителя, затем сорбция замедляется. У красителя Е131 плато слабо выражено, вероятно, это связано с различным расположением молекул красителя на поверхности полимера [10].

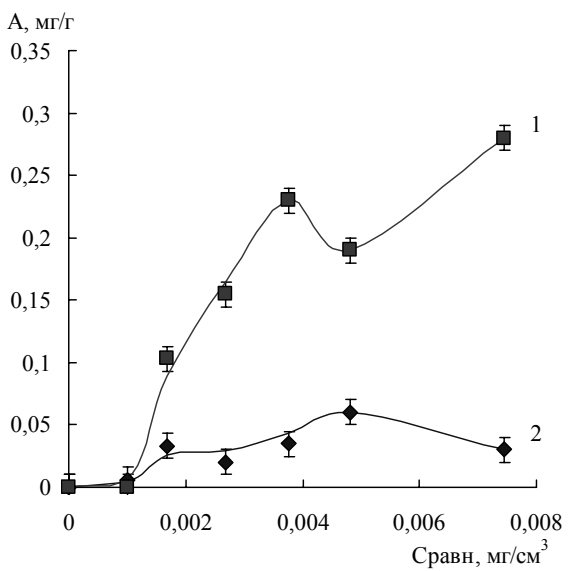

Рис. 1. Изотерма сорбции красителя синего патентованного V (Е131): 1-полимер с молекулярными отпечатками красителя, 2- полимер сравнения.

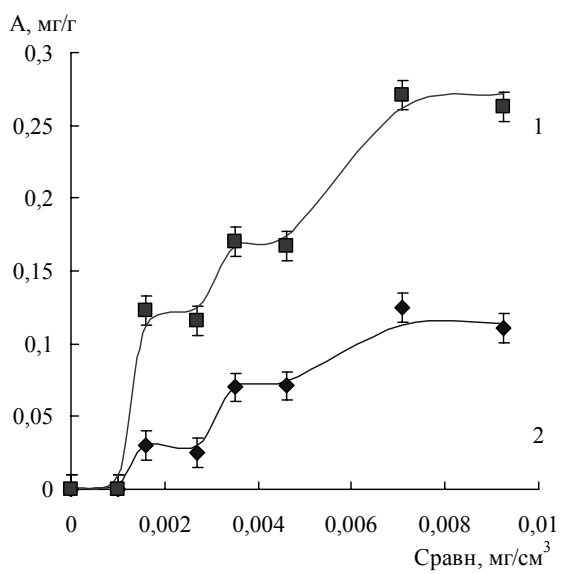

Рис. 2. Изотерма сорбции красителя синего блестящего FCF (Е133): 1-полимер с молекулярными отпечатками красителя, 2- полимер сравнения.

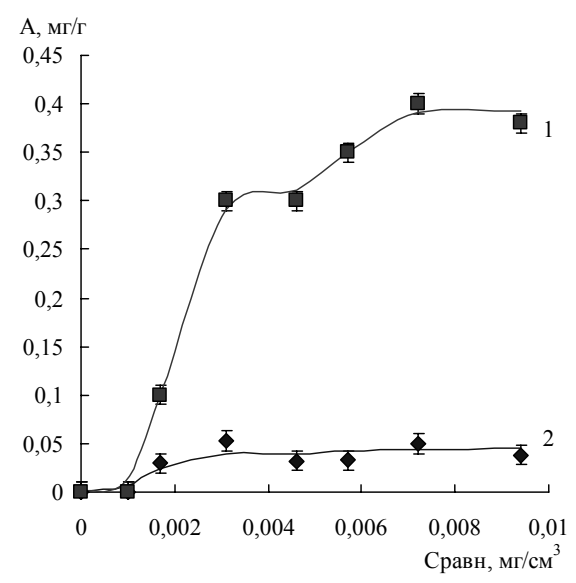

Рис. 3. Изотерма сорбции красителя зеленого S (E142): 1 - полимер с молекулярными отпечатками красителя, 2 - полимер сравнения. 
Для триарилметановых красителей E133 (рис. 2) и E142 (рис. 3) вид изотермы сорбции характерен для полимерных материалов, имеющих мезопоры. На начальном участке изотермы происходит образование мономолекулярного слоя. Далее происходит постепенное формирование полислоев до тех пор, пока поры не заполнятся молекулами красителей, после чего сорбция завершается [4]. Параллельная ориентация молекул красителя приводит к занятию активных центров полимера при малых концентрациях и поэтому приводит к образованию изотермы L-типа [11]. На изотерме сорбции имеется несколько горизонтальных плато, соответствующих сорбции разных ионных форм красителя. Рассчитанные степени извлечения, коэффициенты распределения и импринтинг-фактор представлены в таблице 1.

Таблица 1. Степени извлечения (R\%), коэффициенты распределения (D) красителей на полимерах с молекулярными отпечатками и их полимерах сравнения (ПC) и значение импринтинг-фактора (IF)

\begin{tabular}{|c|c|c|c|c|c|c|c|}
\hline Сорбент & Краситель & $\mathrm{R}, \%$ & $\mathrm{~S}_{\mathrm{r}}, \%$ & $\mathrm{D}$, дм $^{3} / \Gamma$ & $\mathrm{S}_{\mathrm{r}}, \%$ & IF & $\mathrm{S}_{\mathrm{r}}, \%$ \\
\hline ПС & \multirow{2}{*}{ E131 } & 15.5 & 3.6 & 0.018 & 3.1 & \multirow{2}{*}{3.5} & \multirow{2}{*}{4.2} \\
\hline ПМО-Е131 & & 74.5 & 2.6 & 0.061 & 3.8 & & \\
\hline$\Pi \mathrm{\Pi C}$ & \multirow{2}{*}{ E133 } & 20.0 & 3.4 & 0.018 & 2.7 & \multirow{2}{*}{4.7} & \multirow{2}{*}{3.1} \\
\hline ПМО-Е133 & & 80.8 & 3.9 & 0.083 & 3.6 & & \\
\hline$\Pi \mathrm{\Pi C}$ & \multirow{2}{*}{ E142 } & 5.0 & 4.1 & 0.018 & 2.3 & \multirow{2}{*}{5.3} & \multirow{2}{*}{3.2} \\
\hline ПМО-Е142 & & 78.5 & 3.2 & 0.096 & 3.4 & & \\
\hline
\end{tabular}

Из таблицы видно, что значения импринтинг-фактора для полимеров с молекулярными отпечатками красителей увеличиваются в ряду: E131<E133<E142. В водном растворе у красителя Е142 при переходе от биполярного иона к однозарядному аниону нарушается пространственная симметрия молекулы и происходит перераспределение электронной плотности в хиноидном кольце, что существенно влияет на сорбцию красителя. Увеличение числа бензольных колец в молекуле красителя Е131 приводит к уменьшению сорбции, вероятно, это связано с пространственными нарушениями ориентации молекул красителя в адсорбционном слое сорбента. При сорбции анионных частиц красителей поверхность сорбента приобретает частичный отрицательный заряд, что затрудняет сорбцию при увеличении поверхностной концентрации сорбата. Ориентация молекул красителя в адсорбционном слое, вероятно, близка к параллельной относительно поверхности сорбента.

Площади проекций молекул на поверхность модифицированного полимера (табл. 2) для всех красителей превышают рассчитанные значения площадей молекул, что свидетельствует о неплотном заполнении поверхности сорбента.

Таблица 2. Максимальная емкость $(\mathrm{Am})$, удельная поверхность ПМО $\left(\mathrm{S}_{\mathrm{yд}}\right)$ и площадь поверхности $\mathrm{S}_{\mathrm{i}}$ сорбента, приходящаяся на молекулу красителя.

\begin{tabular}{|c|c|c|c|c|}
\hline Краситель & $\mathrm{S}_{0}{ }^{*}, \mathrm{HM}^{2}$ & $\mathrm{~S}_{\mathrm{yд}}, \mathrm{M}^{2} / \Gamma$ & $\mathrm{A}_{\mathrm{m}}$, мкмоль/Г & $\mathrm{S}_{\mathrm{i}}, \mathrm{HM}^{2}$ \\
\hline Синий патентованный V, E131 & 4.73 & 25.36 & 0.48 & 87.8 \\
\hline Синий блестящий FCF, E133 & 5.82 & 9.95 & 0.38 & 43.5 \\
\hline Зеленый S, E142 & 4.70 & 33.2 & 0.69 & 79.9 \\
\hline
\end{tabular}

* Площадь молекулы красителя рассчитана по методике [12].

Площадь проекции молекулы красителя E133 на поверхность модифицированного полимера имеет наименьшее значение, что свидетельствует о

$\boldsymbol{X}$ Хльзова и др. / Сорбционные и хроматографические процессы. 2017. Т. 17. № 2 
пространственных затруднениях при ориентации молекулы красителя на поверхности сорбента.

\section{Заключение}

Таким образом, полимеры с молекулярными отпечатками на основе полиимида обладают лучшей сорбционной способностью по отношению к целевым молекулам, чем их полимеры сравнения. В ходе исследования процесса сорбции триарилметановых красителей полимерами с молекулярными отпечатками было выявлена, что лучшей сорбционной способностью обладает полимер с молекулярными отпечатками красителя зеленый S (E142).

\section{Список литературы}

1. Маюрникова Л.А., Куракин М.С. Пищевые и биологически активные добавки. Кемерово, Кемеровский технологический институт пищевой промышленности. 2006. 124 c.

2. Мишина А.А., Зяблов А.Н., Селеменев В.Ф. // Известия Вузов. Серия: Химия и химическая технология. 2010. Т. 53. № 4. С. 2024.

3. Зяблов А.Н., Дуванова О.В., Володина Л.В., Селеменев В.Ф. и др. Патент РФ № 137946, 2014.

4. Грег С., Синг К. Адсорбция, удельная поверхность, пористость. М. Мир. 1984.306 c.

5. Кудринская В.А., Дмитриенко С.Г. // Сорбиионные и хроматографические проuессы. 2009. Т. 9. № 6. С. 824-829.

6. Яшкин С.Н., Кольцов Л.В., Лосева М.А. Молекулярная адсорбция на границе раздела

\section{References}

1. Mayurnikova L.A., Kurakin M.S. Pishchevye i biologicheski aktivnye dobavki. Kemerovo, Kemerovskii tekhnologicheskii institut pishchevoi promyshlennosti, 2006, $124 \mathrm{p}$.

2. Mishina A.A., Zyablov A.N., Selemenev V.F., Izvestiya Vuzov. Seriya: Khimiya i khimicheskaya tekhnologiya, 2010, Vol. 53, No 4, pp. 20-24.

3. Zyablov A.N., Duvanova O.V., Volodina, L.V., Selemenev V.F. et al. Patent RF № 137946, 2014.

4. Greg S., Sing K. Adsorbtsiya, udel'naya poverkhnost', poristost'. M., Mir, 1984, 306 p. «жидкий раствор - твёрдый адсорбент. Самара. Самарский государственный технический университет. 2012. 14 с.

7. Когановский, А.М., Левченко Т.М., Кириченко В.А. Адсорбция растворенных веществ. Киев. Наукова думка. 1977. 224 с.

8. Гендриксон О.Д., Жердев А.В., Дзантиев Б.Б. // Успехи биологической химии. 2006. T. 46. C. 149-192.

9. Коршак В. В. Термостойкие полимеры. М. Наука. 1969. 414 с.

10.Митрофанова Н.В., Нечаев А.Н., Хохлова Т.Д., Мчедлишвили Б.В. // Коллоидный журнал. 2003. Т. 65. № 2. С. 248- 251.

11.Липатов Ю.З., Сергеева Л.С. Адсорбция полимеров. Киев. Наукова думка. 1972.196 с.

12.Гершензон Е.М., Малов Н.Н., Мансуров А.Н. Молекулярная физика. М. Академия. 2000. $274 \mathrm{c}$.

5. Kudrinskaya, V.A., Dmitrienko, S.G., Sorbtsionnye i khromatograficheskie protsessy, 2009, Vol. 9, No 6, pp. 824-829.

6. Yashkin S.N., Kol'tsov L.V., Loseva M.A. Molekulyarnaya adsorbtsiya na granitse razdela «zhidkii rastvor - tverdyi adsorbent. Samara, Samarskii gosudarstvennyi tekhnicheskii universitet, 2012, $14 \mathrm{p}$.

7. Koganovskii, A.M., Levchenko T.M., Kirichenko V.A. Adsorbtsiya rastvorennykh veshchestv. Kiev, Naukova dumka, 1977, 224 p.

8. Gendrikson O.D., Zherdev A.V., Dzantiev B.B., Uspekhi biologicheskoi khimii, 2006, Vol. 46, pp. 149-192. 
9. Korshak V.V. Termostoikie polimery. 11. Lipatov Yu.Z., Sergeeva L.S., Adsorbtsiya Moskva, Nauka, 1969, 414 p.

10. Mitrofanova N.V., Nechaev A.N., Khokpolimerov. Kiev, Naukova dumka, 1972, 196 p.

hlova T.D., Mchedlishvili B.V., Kolloidnyi zhurnal, 2003, Vol. 65, No 2, pp. 248 - 251.

12. Gershenzon E.M., Malov N.N., Mansurov A.N. Molekulyarnaya fizika. Moskva, Akademiya, 2000, $274 \mathrm{p}$.

Хальзова Светлана Александровна - аспирант кафедры аналитической химии, Воронежский государственный университет; Воронеж

Дуванова Ольга Васильевна - к.Х.н., ведущий инженер кафедры аналитической химии, Воронежский государственный университет, Воронеж

Зяблов Александр Николаевич - д.Х.н., профессор кафедры аналитической химии, Воронежский государственный университет, Воронеж

Khalzova Svetlana A. - postgraduate student department of analytical chemistry, Voronezh State University, Voronezh, e-mail: ahalzov@mail.ru

Duvanova Olga V. - Ph.D. (Chem.), leading engineer Department of analytical chemistry Voronezh state University, Voronezh

Zyablov Alexander N. - Dr. Sci.(Chemistry), professor Department of Analytical Chemistry, Voronezh State University, Voronezh 